\title{
EchoGéo
}

11 | 2010

Madagascar

\section{Les enjeux du Pacifique}

Ouvrage sous la direction de Patrice Cosaert

\section{(2) OpenEdition}

\section{Journals}

\section{Édition électronique}

URL : https://journals.openedition.org/echogeo/11631

DOI : 10.4000/echogeo.11631

ISSN : 1963-1197

\section{Éditeur}

Pôle de recherche pour l'organisation et la diffusion de l'information géographique (CNRS UMR 8586)

\section{Référence électronique}

«Les enjeux du Pacifique », EchoGéo [En ligne], 11 | 2010, mis en ligne le 24 février 2010, consulté le 01 août 2021. URL : http://journals.openedition.org/echogeo/11631; DOI : https://doi.org/10.4000/ echogeo.11631

Ce document a été généré automatiquement le 1 août 2021.

EchoGéo est mis à disposition selon les termes de la licence Creative Commons Attribution - Pas d'Utilisation Commerciale - Pas de Modification 4.0 International (CC BY-NC-ND) 


\section{Les enjeux du Pacifique}

\section{Ouvrage sous la direction de Patrice Cosaert}

1 Patrice Cosaert, professeur émérite de l'université de La Rochelle, spécialiste de l'aire Pacifique a rassemblé dans ce livre les contributions de géographes, historiens, économistes, linguistes. Après une introduction en forme d'interrogation sur le degré d'intégration dans un ensemble régional des pays bordant le grand océan, l'ouvrage décline cette thématique en quatorze dossiers.

2 Sont abordés successivement:

- Les conséquences spatiales de la Seconde Guerre Mondiale,

- Les échanges maritimes entre les rives du Pacifique,

- L'apparition et l'impact du tourisme,

- L'émergence et la croissance économique de la Chine,

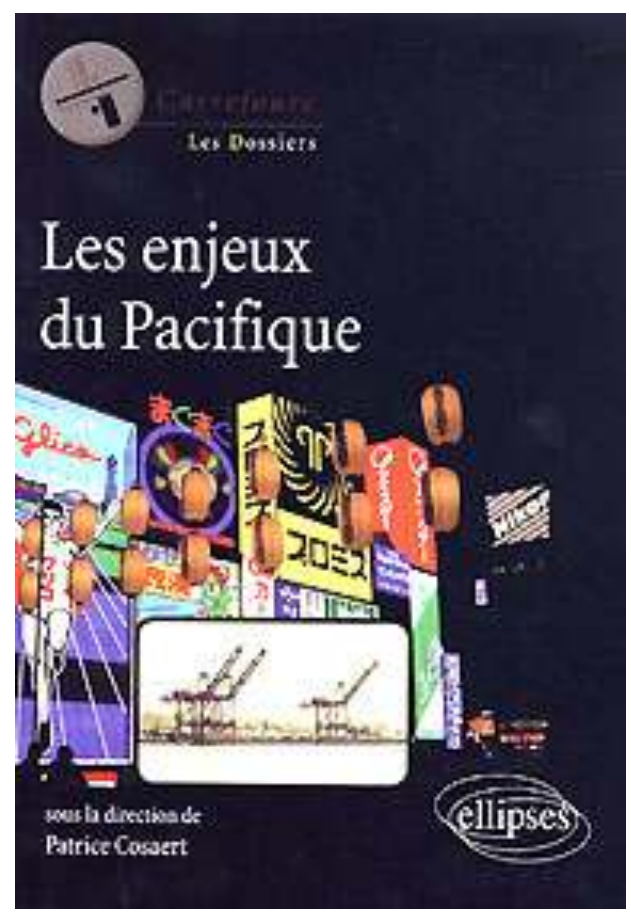

- La place des Etats-Unis dans cet ensemble régional,

- L'évolution des relations entre le Canada, les Etats-Unis et l'Asie du Sud est,

- Les rôles respectifs du Japon, de la Corée, de Taiwan, des pays de l'ASEAN, de l'Australie,

- Les enjeux et perspectives pour l'Amérique Latine dans ce contexte.

Plusieurs dossiers mettent en évidence la montée en puissance de la Chine. Est également abordé le rôle joué par l'émigration chinoise depuis le $19^{\mathrm{e}}$ siècle, les conséquences actuelles de ce phénomène sur la structuration de l'espace Pacifique.

4 La question du leadership américain, de ses formes et de sa durée, apparaît en filigrane dans tous les chapitres. 
5 En conclusion, la synthèse ébauchée par Patrice Cosaert relève les complémentarités entre les aires atlantique et pacifique. Il s'interroge sur les découpages qui fluctuent au gré des alliances politiques et commerciales et sur les structures des organisations intergouvernementales: ASEAN, APEC.

6 Bernadette Joseph

BIBLIOGRAPHIE

Les enjeux du Pacifique, sous la directionde Patrice Cosaert. Paris : Ellipses, 2009, 352 p., $23 \mathrm{~cm}$ (Collection Carrefours : les dossiers). ISBN : 978-2-7298-4399-1 